\title{
GÊNEROS DIGITAIS EM LIVROS DIDÁTICOS DE PORTUGUÊS: UMA ABORDAGEM FOCADA NO LIVRO DIDÁTICO E NA CONCEPÇÃO DE PROFESSORES ${ }^{1}$
}

\author{
Nádson Araújo dos Santos* \\ Maria Auxiliadora da Silva Cavalcante**
}

RESUMO: Este artigo é síntese de uma dissertação de Mestrado em Educação, que teve como objetivo analisar os gêneros textuais digitais que são abordados pelos livros didáticos de língua portuguesa, nos anos finais do ensino fundamental. É uma pesquisa qualitativa do tipo estudo de caso e foi desenvolvida em uma escola pública da rede municipal de ensino, em uma cidade do litoral sul do Estado de Alagoas. Para atingir o objetivo, foi realizada análise documental e encontros em grupos focais com professores de língua portuguesa que atuavam no ensino fundamental. Os procedimentos metodológicos utilizados foram a análise documental de volumes de livros didáticos do sexto ao nono ano do ensino fundamental, bem como entrevistas com professores. Para compreender os conceitos dos gêneros do discurso, tomamos por base Bakhtin (1997, 2016), Marcuschi (2008, 2010) e Miller (2012). Quanto aos saberes específicos dos gêneros digitais apoiamo-nos em Marcuschi e Xavier (2010). Os resultados apontam que os livros didáticos do sexto ao nono ano apresentam os gêneros digitais, no entanto, somente no livro do sexto ano é que esse tipo de gênero é trabalhado de uma forma mais significativa, nos demais eles são citados como pretexto para trabalhar outras categorias linguísticas. Apontam também que os manuais didáticos para o ensino fundamental orientam quanto a utilização dos gêneros digitais nas aulas do ensino fundamental. Também constatamos que os professores possuem uma percepção positiva do livro didático utilizado pela escola e que possuem conhecimento sobre os gêneros digitais e os utilizam em práticas.

PALAVRAS-CHAVE: Língua Portuguesa; Livro Didático; Gêneros Digitais.

\section{Primeiras palavras}

Estamos inseridos num contexto social em que as tecnologias digitais da informação e comunicação (TDIC) têm perpassado por diversos setores na chamada sociedade da

\footnotetext{
${ }^{1}$ Este artigo é síntese de uma pesquisa em nível de Mestrado realizada entre 2017-2019 no Programa de PósGraduação em Educação.

${ }^{*}$ Doutorando e Mestre em Educação pelo Programa de Pós-graduação em Educação da Universidade Federal de Alagoas (Ufal). Professor Substituto da Ufal. Membro do grupo de pesquisa e estudo em didática de leitura, da literatura e da escrita, e do grupo de pesquisas e estudos em variação linguística, leitura e escrita.

** Doutora em Letras e Linguística pelo Programa de Pós-graduação em Letras e Linguística da Universidade Federal de Alagoas (Ufal). Pós-Doutora em Educação pela Universidade do Porto/Portugal. Professora Associada IV da Ufal. Líder do grupo de pesquisas e estudos em variação linguística, leitura e escrita.
} 
informação e do conhecimento. Nesse cenário, os estudos sobre linguagem assumem um papel fundamental, seja no desenvolvimento de metodologias para o ensino da leitura ou mesmo para subsidiar análises da escrita, transformando lugares, pensamentos, concepções e vivências. Com isso, as novas interfaces midiáticas têm se incorporado ao ambiente escolar, propondo mudanças significativas em suas estruturas física, pedagógica e funcional (LÉVY, 1999), que são típicas da sociedade da cultura digital. Segundo Lévy (1999), essas mudanças fazem parte do processo de apropriação de uma cultura que a cada dia se estabelece entre nós, permitindo uma interação com espaços emergentes, que Levy (1999) chama de ciberespaço. No ciberespaço, essas mudanças são carregadas de significados, de símbolos e sinais gráficos, que propiciam aproximação entre falantes e escreventes, utilizando uma linguagem hipertextual, dotada de domínio discursivo das tecnologias digitais da informação e comunicação (TDIC).

O estudo sobre os gêneros do discurso vem sendo realizado por diversas áreas de investigação, tais como: a literatura, a sociologia, a análise do discurso, linguistas da computação e outros cientistas, fazendo desse campo de estudo uma área multidisciplinar, que procura abordar os usos da linguagem no cotidiano. Dados históricos apresentam os filósofos Aristóteles e Platão como sendo os primeiros estudiosos a apresentarem o conceito de gênero do discurso. Quando observamos o que expõe Marcuschi (2008), vemos que a expressão "gênero" estava primeiramente ligada aos gêneros literários e era discutida por filósofos da Grécia Antiga até os primórdios do século XX.

A expressão "gênero" esteve, na tradição ocidental, especialmente ligada aos gêneros literários, cuja análise se inicia com Platão para se firmar com Aristóteles, passando por Horácio e Quintiliano, pela Idade Média, o Renascimento e a Modernidade, até os primórdios do século XX. (MARCUSCHI, 2008, p. 147)

O autor acrescenta que atualmente o estudo dos gêneros não está somente vinculado a literatura, por se referir a uma categoria distintiva de discurso falado ou escrito com expirações literárias ou não. Marcuschi (2008) nos apresenta uma teoria sistematizada sobre os gêneros, expondo os três elementos que compõem o discurso: aquele que fala, aquilo sobre o que se fala e aquele a quem se fala. Marcuschi também apresenta três tipos de 
ouvintes: aquele que, como um expectador, olha para o presente; o outro que, como assembleia, olha para o futuro e aquele que como o juiz tem uma perspectiva de julgamento sobre coisas do passado. Segundo Marcuschi (2008), essa visão aristotélica foi amplamente desenvolvida na Idade Média.

Ampliando a discussão sobre o conceito de gênero, observamos em Bakhtin (2016) que o emprego da língua se dá pelos enunciados, ou pela forma de enunciados, tanto na modalidade oral quanto na escrita, refletindo condições específicas e finalidades de cada campo, pelo conteúdo e pelo estilo da linguagem, mas sobretudo, pela sua construção composicional, cada enunciado particular é individual, e cada campo de utilização da língua se utiliza de tipos relativamente estáveis de enunciados, os quais o autor denomina gêneros do discurso. Sendo assim, vimos em Bakhtin (2016) que todo gênero possui três características: unidade temática, estilo e estrutura composicional. Para Bakhtin (2016, p. 12),

a diversidade dos gêneros do discurso é infinita porque são inesgotáveis as possibilidades da multifacetada atividade humana e porque em cada campo dessa atividade vem sendo elaborado todo um repertório de gêneros do discurso, que cresce e se diferencia à medida que tal campo se desenvolve e ganha complexidade. Cabe salientar em especial a extrema heterogeneidade dos gêneros do discurso (orais e escritos).

É através da diversidade e da heterogeneidade dos gêneros discursivos que podemos observar a função social dos gêneros, que merece atenção e estudo particulares. Em sua obra, intitulada - os gêneros do discurso - Bakhtin (2016) apresenta a diferenciação dos gêneros primários e secundários, como gêneros simples e complexos respectivamente. De acordo com Miller (1984, p. 165), os gêneros são uma forma de ação ou função social. Podemos observar esse pensamento quando o autor afirma que:

O que aprendemos quando aprendemos um gênero não é apenas um padrão de formas ou um método para realizar os nossos propósitos. Aprendemos, isto é o mais importante, quais propósitos podemos ter [...]; para o estudante, os gêneros servem de chave para entender como participar das ações de uma comunidade. (MILLER, 1984, p. 165) 
Assim, com base em Miller (1984), compreendemos que os gêneros permitem ao indivíduo interagir com a sociedade, e através dessas relações de interação, estabelecer as práticas sociais, colocando-se por meio de um estilo mais apropriado para o domínio discursivo corrente, compondo seu enunciado de forma a atender a situação e a complexidade das interações que as multifaces da linguagem exigem. Bazerman (2011, p. 23) traz uma abordagem também quanto aos gêneros, o autor afirma que eles os gêneros não são apenas formas². Bazeman defende que os gêneros são formas de vida, modos de ser. O autor dialoga, nesse sentido, com o pensamento de Miller (1984) quando afirma que os gêneros são frames $^{3}$ para a ação social, ambientes para a aprendizagem. Nessa perspectiva, Bazerman (2011, p. 31) afirma que:

O gênero é uma ferramenta para descobrir os recursos que os alunos trazem consigo, ou seja, os gêneros que trazem de sua formação e de sua experiência na sociedade. É também uma ferramenta para definir os desafios que levarão os alunos a novos domínios até então não explorados por eles.

Baseados na assertiva de Bazerman (2011), podemos afirmar que o ensino dos gêneros textuais em sala de aula pode ajudar os alunos a explorar um habitat linguístico além daquele pertencente ao seu próprio discurso ou domínio discursivo, ampliando assim saberes e possibilidades de aprendizagem. Nesse sentido, observamos a importância de os gêneros do discurso estarem presentes nos eixos de ensino de Língua Portuguesa (LP) nas escolas e promovendo a discussão conceitual e atitudinal dos gêneros, como apresentado pelos teóricos (MARCUSCHI, 2008; BAZERMAN, 2011).

Os gêneros do discurso se materializam na oralidade e na escrita, nos mais diversos domínios discursivos. Vale ressaltar que os gêneros não são estáticos, eles estão sempre em movimento, e esse movimento está diretamente relacionado com a evolução social, exercendo seu fator social como afirma Miller (1984). A sociedade está em constante evolução social e os gêneros acompanham esse movimento.

\footnotetext{
${ }^{2}$ Charles Bazerman (2011) refere-se a forma no sentido de modelos prontos e acabados de textos, moldes.

${ }^{3}$ Modelos, moldes.
} 


\section{Gêneros digitais: a transmutação dos gêneros discursivos}

Na sociedade pós-moderna, a materialização dos enunciados em meios digitais é de fato uma realidade que se observa pelo uso exaustivo de recursos tecnológicos e aplicativos virtuais, seja para fins pessoais ou profissionais. De forma geral, pesquisas realizadas, Borges (2017), Marcuschi e Xavier (2010) e Pimentel e Costa (2017), mostram que os gêneros digitais estão consolidados na linguagem oral, tais como em podcasts e mensageiros instantâneos, e na linguagem escrita, como o blog e os posts digitais. Marcuschi (2010, p. 15) classifica-os como gêneros textuais emergentes no contexto da tecnologia digital. Nesse sentido, expõe o autor:

Sequer se consolidaram, esses gêneros eletrônicos já provocam polêmicas quanto a natureza e proporção do seu impacto na linguagem e na vida social. Isso porque os ambientes virtuais são extremamente versáteis e hoje competem, em importância, entre as atividades comunicativas, ao lado do papel e do som. Em certo sentido, pode-se dizer, que na atual sociedade da informação, a internet é uma espécie de protótipo de novas formas de comportamento comunicativo. (MARCUSCHI, 2010, p. 15)

Dialogando com Bakhtin (2016), Miller (1984) e Marcuschi (2010), retomamos os gêneros do discurso como fator social, pois esses teóricos ratificam o impacto que os gêneros podem provocar na linguagem e na vida social dos indivíduos. Há concomitantemente uma preocupação com a força que esses novos gêneros possuem, uma vez que a apropriação desses gêneros pode ampliar a competência comunicativa do indivíduo.

Os gêneros textuais de forma geral possuem um correspondente preexistente, que transmutam através do tempo, causando nos indivíduos uma ideia de continuidade, evolução ou mutação do gênero. Contudo, vale ressaltar que apesar de existir esse comparativo entre eles, há também distintas características que os diferenciam, conforme afirma Marcuschi (2010, p. 37), “esses gêneros têm características próprias e devem ser analisados em particular. Nem sempre têm uma contraparte muito clara e não se pode esperar uma especularidade na projeção de domínios tão diversos como são o virtual e o real tradicional”. 


\section{E-mail, chat online e blog: a função social dos gêneros emergentes digitais}

O termo e-mail é bastante utilizado pela sociedade contemporânea, a expressão é derivada da língua inglesa - eletronic mail - o mesmo termo é utilizado em referência ao sistema de transmissão e, por metonímia, para o texto produzido com esse fim, é também utilizado para se referir ao endereço eletrônico de cada usuário. Nessa perspectiva, o e-mail ou a mensagem eletrônica, geralmente é produzido pelo emissor da mensagem, que por sua vez envia diretamente, de forma assíncrona e online ao receptor destinatário. Segundo Paiva (2010, p. 86), o e-mail surgiu em 1971, quando Ray Tomlinson enviou a primeira mensagem de um computador para o outro, para isso, ele utilizou o programa SNDMSG que tinha acabado de desenvolver. Foi Tomlinson que escolheu o símbolo@ (arroba) para sinalizar o endereço de cada usuário. Além de criar o programa SNDMSG para o envio de e-mails, desenvolveu também o READ-MAIL para a sua leitura. Paiva (2010, p. 87) acrescenta que as mensagens eletrônicas são o tipo de texto mais produzido na atualidade nas sociedades letradas, devido a seu aspecto prático, usual e interativo.

Do ponto de vista pedagógico e observando o aspecto estrutural, o e-mail pode ser utilizado como uma metodologia ativa para produção hipertextual, permitindo a exploração de competências linguísticas para além da produção tradicional de textos nas escolas.

O chat online, por sua vez, é uma metodologia ativa bastante útil e difundida na sociedade atual, podemos citar o aplicativo Whats App que é sem dúvida um excelente exemplo desse tipo de aplicativo. Esse tipo de aplicativo permite a produção textual, o compartilhamento em tempo real das produções, a coautoria e a produção coletiva. Os chats, seja pela sua versatilidade e praticidade, bem como por sua multiplataforma, podem ser executados em microcomputadores e smartphones e possuem uma excelente aceitabilidade na sociedade contemporânea. Os chats também possuem um potencial significativo diferenciado do texto hipermodal, de acordo com Braga (2010, p. 175)

o texto hipermodal, ao relacionar dentro de uma estrutura hipertextual unidades de informação de natureza diversa (texto verbal, som, imagem), gera uma nova realidade comunicativa que ultrapassa as possibilidades interpretativas do gênero dos gêneros multimodais tradicionais. 
Xavier (2010) e Araújo (2010) apresentam possibilidades e limitações para o uso do chat na produção hipertextual na sala de aula, em contextos de ensino e aprendizagem, segundo esses autores é possível explorar o hipertexto no contexto pedagógico, afirmam que a leitura de hipertextos permite ao leitor a escolha de caminhos, exige desse a participação na construção dos aspectos de coesão e coerência do texto, levando-o ao engajamento (no sentido de participação efetiva) nas atividades. Quando do estudo dos gêneros digitais, não podemos desassociar a discussão da concepção temática multimodal, que por sua vez se utiliza da linguagem hipertextual para se materializar, os chats online por sua vez são, hipertextuais e multimodais.

Outra metodologia ativa e também gênero textual emergente digital é o blog, que, a princípio, foi criado com o objetivo principal de popularizar publicações de textos online, com uma interface intuitiva. Com o avançar dos usos e das tecnologias digitais, sobretudo, as ferramentas de edição do blog que facilitam a produção, edição e publicação de textos, o blog atualmente, dispensa conhecimentos mais específico e avançado em computação, como refere Komesu (2010, p. 136), quando afirma que

A facilidade para a edição, atualização e manutenção dos textos em rede foi - e é - os principais atributos para o sucesso e a difusão dessa chamada ferramenta de auto expressão. A ferramenta permite, ainda, a convivência de múltiplas semioses, a exemplo de textos escritos, de imagens (fotos, desenhos, animações) e de som (músicas, principalmente)

Com base em Komesu (2010), constatamos que a versatilidade dos recursos do blog, no processo ensino e aprendizagem, sobretudo a facilidade de acesso e sua utilização, otimizam o uso de metodologias ativas, que são mais utilizadas atualmente. Ainda do ponto de vista pedagógico, percebemos que o blog é um espaço de autonomia, de poder, e de expressar por meio da atividade de produção textual (verbal e não-verbal), a liberdade em poder escolher sons e imagens, vinculando-os ao próprio texto, instaurando dessa forma um diferencial dos blogs, que conquistam cada vez mais aderentes. 
O Blog pode ser utilizado de diversas formas sem perder o aspecto pedagógico dos processos de ensino e aprendizagem, nas atividades de produção textual, de narrativas digitais, nas leituras individual e coletiva. Sendo assim, essa metodologia ativa pode ser utilizada para potencializar as aulas de Língua Portuguesa, contemplando as concepções dos multiletramentos e da multimodalidade, pois segundo Oliveira e Dias (2016), utilizando vídeos, sons e imagens podemos criar diversas configurações que otimizam o uso das linguagens verbal e não-verbal, o que reafirma a caraterística multifacetada do gênero.

\section{Percurso metodológico da pesquisa: abordagem, natureza e instrumentos}

A pesquisa que deu origem a este artigo é uma pesquisa qualitativa (ALVES MAZZOTI; GEWANDSNAJDER, 2004), que teve como objetivo principal analisar os gêneros textuais digitais em livros didáticos de Língua Portuguesa do ensino fundamental, em relação à concepção teórica de gênero discursivo, bem como, analisar a concepção dos professores que utilizam os livros analisados. Foi realizada entre 2017-2019 em uma escola pública municipal localizada no litoral sul do Estado de Alagoas. A abordagem é do tipo estudo de caso (YIN, 2005), uma vez que se ocupa em analisar fatos contemporâneos da sociedade, sobre esta natureza de pesquisa afirma Yin (2015).

Ao longo da pesquisa, foram realizadas visitas a escola lócus da pesquisa, entrevistas com os professores, além da análise dos documentos oficiais, tais como: livros didáticos, planos de aulas, PCN e BNCC do ensino fundamental (BRASIL, 1998, 2017).

Foi adotado como procedimento metodológico para coleta de dados, a formação de um grupo focal que, segundo Gatti (2005), no âmbito das abordagens qualitativas é uma técnica bastante utilizada, além de entrevistas semiestruturadas e revisão documental. Os critérios para a seleção dos professores colaboradores da pesquisa foram preestabelecidos com o sentido de criar um perfil do grupo para que assim pudessem dialogar entre pares.

A técnica de análise utilizada foi a Análise Textual Discursiva - ATD (MORAES; GALIAZZI, 2016) que segundo os autores opera com significados construídos a partir de um conjunto de textos a que o analista precisa atribuir sentido e significados, ou seja, ana- 
lisamos um conjunto de textos (nos livros didáticos, gravações do grupo focal, das entrevistas semiestruturadas) no sentido de discorrer sobre o objeto de estudo, contrapondo os achados da pesquisa com o corpo teórico.

\section{Achados: o (não) lugar dos gêneros digitais no livro didático de Português}

A coleção analisada ${ }^{4}$ é distribuída em quatro volumes, correspondendo aos níveis do sexto ao nono ano dos anos finais do ensino fundamental, receberam a nomenclatura de volume seis, sete, oito e nove. A obra de volume seis de Cereja e Magalhães (2015a) com 272 páginas é subdividida em quatro grandes unidades e estas subdivididas nos seguintes eixos: Estudo do texto, produção de texto, a língua em foco e divirta-se.

O livro didático de Português correspondente ao sexto ano apresenta pela primeira vez na página 44 o primeiro gênero textual digital - o e-mail. Esse gênero aparece no capítulo dois do livro didático, na seção em que se discute a variação linguística na oralidade e na escrita. Os autores utilizam o gênero para exemplificar contextos de comunicação formal e informal e os graus de monitoramento da oralidade. Observe na próxima ilustração, a abordagem do material didático.

Ilustração 1 - Atividade utilizando o E-mail.

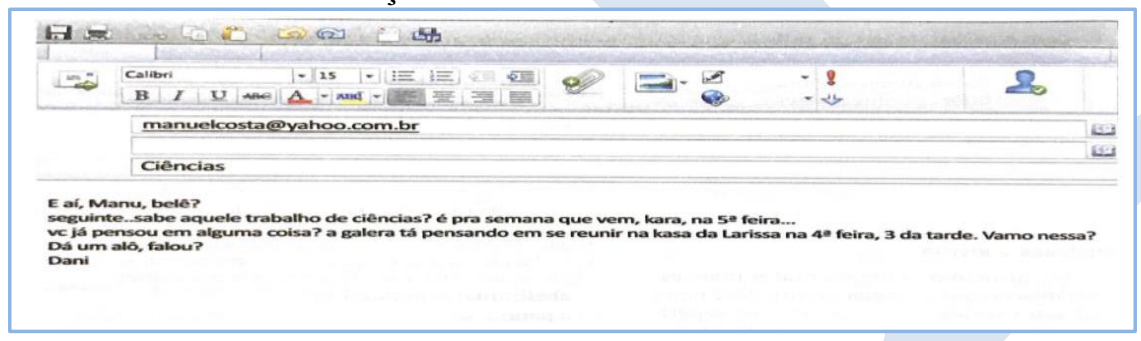

Fonte: Reprodução LDP Linguagens. Cereja e Magalhães (2015a, p. 44)

\footnotetext{
${ }^{4}$ A coleção Português: linguagens foi aprovada, recomendada e distribuida pelo Programa Nacional do Livro e Material Didático (PNLD) para o triênio 2017-2019.
} 
Como apresentamos na introdução deste artigo, Bazerman (2011) aponta o gênero como o meio pelo qual os indivíduos interagem entre si, no diálogo exposto na ilustração 6, é possível fazer essa relação, pois o e-mail é utilizado pelos autores do livro para discutir a função comunicativa através da interação entre as amigas Manu e Deni. No livro, o foco é a informalidade da comunicação entre as amigas. Vale ressaltar, que o trecho se encontra no eixo em que se discute a variação linguística, enfatizando a forma como elas se comunicam. Quando contrapomos com o conceito de Miller (1984), o livro didático atende ao que o ator chama de função social, ao frisar que o gênero $e$-mail permitir a interação entre as estudantes.

No capítulo dois do volume seis, da mesma coleção, especificamente na página 179, os autores abrem uma seção com uma proposta de produção de texto, inserindo o conteúdo - Os Gêneros Digitais: E-mail, blog, twitter, comentário. Na abordagem, o material inicia com a apresentação do e-mail. A partir de um diálogo entre duas amigas. E na sequência faz alguns questionamentos voltados à competência de análise linguística. Observe na ilustração 7 a seguir, que o diálogo é utilizado na unidade para introduzir o conteúdo dos gêneros digitais, a atividade faz parte da unidade 4, seção em que o livro do sexto ano contempla diretamente o ensino dos gêneros digitais.

Ilustração 2 - E-mail (Diálogo entre amigas).

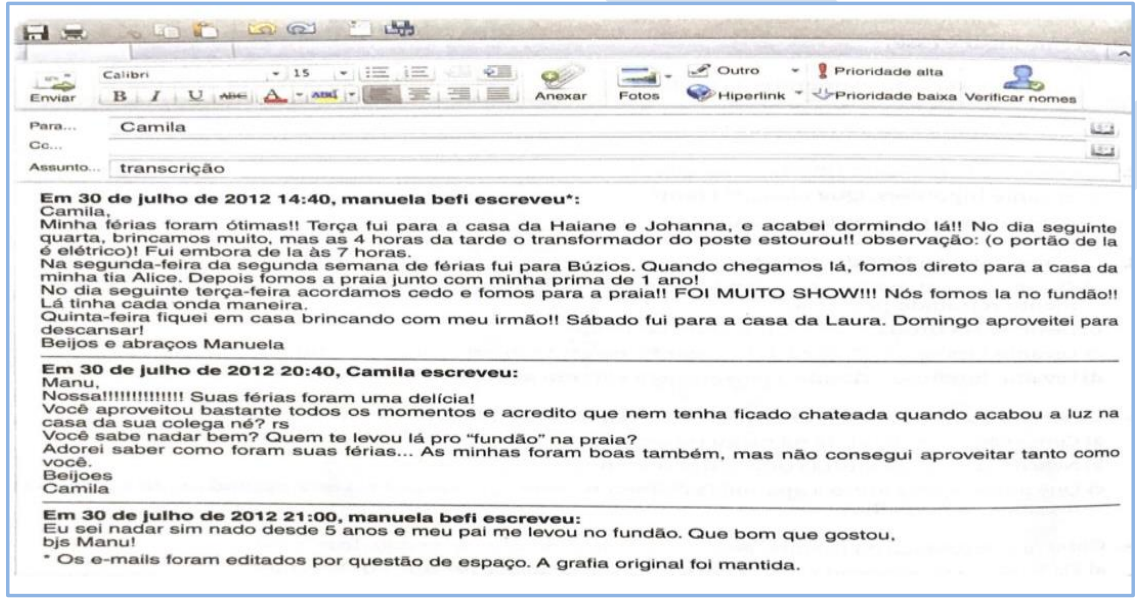

Fonte: Reprodução LDP Linguagens. Cereja e Magalhães (2015a, p. 179) 
Bakhtin (2016) defende que os gêneros têm uma forma, um estilo, uma estrutura composicional. No diálogo entre as amigas (ilustração 7), o livro didático apresenta essa concepção teórica bakhtiniana, pois a forma, a estrutura e o estilo em que o texto se materializa são próprias do gênero em estudo: o -mail.

$\mathrm{Na}$ mesma página, os autores apresentam um quadro explicativo com uma discussão do significado da palavra e-mail, a estrutura do endereço, além de informações da necessidade de acesso à internet, pagamento de taxas e tarifas para usuários.

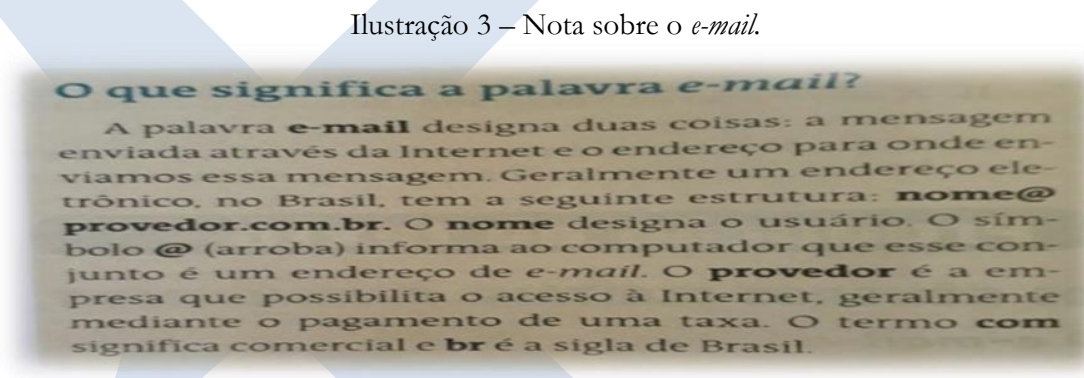

Fonte: Reprodução LDP Linguagens. Cereja e Magalhães (2015a, p. 180)

Cereja e Magalhães (2015a, p. 181) afirmam existir e-mail pessoal e profissional, diferenciado o e-mail pessoal, informando que este é utilizado para tratar de assuntos do cotidiano, destacam ainda as questões das abreviaturas, dos emotions e finaliza convidando os alunos para se reunirem em grupos e responderem ao questionamento: Para que serve o $e$ mail e quais são suas características principais?

Percebemos que nesse momento, o livro didático é direcionado para a abordagem bakhtiana de gênero, quando propõe atividade que permite a discussão da forma composicional do gênero e-mail. Em Cereja e Magalhães (2015a, p. 182), os autores propõem aos alunos a criação de um endereço de e-mail com o auxílio do professor. No enunciado, o material didático apresenta o gênero como meio de comunicação e interação e discute a estrutura da forma, como o uso do vocativo, o assunto principal, expressões de despedida e assinatura. A abordagem do livro didático está de acordo com o que Miller (2012) destaca, quando explica o fator social do gênero e da promoção a interação. 
Marcuschi (2008) apresenta o e-mail como sendo também um suporte de gêneros, pois através dele, outros gêneros podem aparecer, ou utilizar o aspecto hipertextual do $e$ mail para divulgar poemas, notas, recados, bilhetes, anúncios e etc. Nos últimos anos o $e$ mail vem passando por mudanças, as mensagens que outrora transitavam via e-mail, hoje se materializam em outros gêneros, como acontece no twitter, no Whats App, no Instagram, ou seja, o gênero passa por mudanças, confirmando o que defende Bakhtin (1997) sobre a mutabilidade dos gêneros.

O e-mail pode ser ainda um suporte para outros gêneros, ou mesmo um hipergênero, quando admite materializar através dele outros gêneros do discurso.

O volume seis apresenta o gênero digital blog, cujo material didático expõe o gênero, discutindo sua função de diário pessoal, utilizado para publicação de fatos do cotidiano, pensamentos e opiniões, fazendo resgate da evolução sócio-histórica do blog, explica a diferença entre site e blog e encerra a seção convidando os alunos a criarem um blog pessoal ou um blog comunitário. O que nos chama atenção é que os autores abrem um quadro em destaque para diferenciar blog e diário, apontando também as semelhanças entre eles no que diz respeito a função do gênero, mudando apenas as ferramentas de criação, edição e publicação.

Komesu (2010, p. 136) afirma que a "facilidade para a edição, atualização e manutenção dos textos em rede foram - e são - os principais atributos para o sucesso e a difusão da chamada ferramenta de auto expressão", possibilitando que também seja o blog utilizado para uma série de atividades pedagógicas, desde a publicação de textos, eventos de leitura, produção de porffólio e inúmeras atividades. Vale ressaltar que Oliveira e Dias (2016) destacam as concepções de multiletramentos e multimodalidade que essa metodologia ativa pode assumir.

Na página 199, o LDP traz instruções quanto à atividade de criação do blog, indicando inclusive, sites próprios para criação do blog nas orientações da atividade. O LDP orienta aos alunos a publicação de textos produzidos por eles mesmos e divulgar o endereço para suas respectivas famílias. 
Entendemos que esse tipo de abordagem é muito interessante, por fazer com que os alunos, adolescentes, interajam com seus familiares e amigos. Percebe-se que o material didático discorre sobre a função social do gênero, pois orienta quanto as interações sociais, confirmando o que defende Miller (2012), que o gênero é um fator social, pois permite a interação entre os sujeitos e é utilizado para suas práticas sociais.

Ainda na página 199, o LDP apresenta o twitter como um gênero digital e também como uma rede social (na função de suporte de gêneros). O material destaca as possibilidades de interação que o gênero permite, as características de veículo de mensagens curtas e a sua aplicação na pessoalidade dos usuários, na abordagem do chat. Nesse sentido, essa abordagem se aproxima do que disse Braga (2010) quando discorre sobre a versatilidade e usabilidade do aplicativo.

Vimos então que o volume correspondente ao sexto ano, aborda significativamente os gêneros digitais, e-mail, blog e twitter, respondendo assim a primeira pergunta da pesquisa - qual a abordagem dos gêneros digitais em coleções de livros didáticos recomendados pelo PNLD 2017-2019?

Quando analisamos o que preconiza a BNCC do ensino fundamental (BRASIL, 2017), observamos que os gêneros poderiam ser abordados em outros conteúdos e em parceira com as mais diversas competências apontadas pela base, tais como: produção textual, escrita, leitura, análise linguística, dentre outros, pois no mundo do trabalho o gênero como o e-mail por ser muito útil, ou seja, se apropriar desse conhecimento é de grande valia para a atuação no mundo do trabalho e considerando a cultura digital, se apropriar desse conhecimento é indispensável numa sociedade pós-moderna.

No quadro a seguir, apresentamos um quadro síntese dos gêneros digitais no LDP correspondente ao sexto ano do ensino fundamental e o lugar em que aparecem. 
Tabela 1 - Síntese dos gêneros digitais no volume 6 .

\begin{tabular}{|c|l|c|}
\hline Gênero & \multicolumn{1}{|c|}{ Conteúdo } & Página \\
\hline \multirow{2}{*}{ E-mail } & $\begin{array}{l}|c| \\
\text { Variação Linguística. Formalidade e informalidade: graus de monitoramento. } \\
\text { Os Gêneros digitais: E-mail, Blog, twitter, comentário. }\end{array}$ & Página 44 \\
Blog & Os Gégina 179 \\
& Atividade de produção textual e publicação. & Página 182 \\
\multirow{2}{*}{ Twitter } & Os Gêneros digitais: e-mail, blog, twitter, comentário. & Página 199 \\
\hline
\end{tabular}

Fonte: elaborado pelos autores.

Como pudemos observar o gênero e-mail aparece em apenas dois momentos em todo o material didático do sexto ano, o blog também aparece em dois momentos e o twitter somente uma vez. Com isso, podemos afirmar que os gêneros digitais têm um lugar no livro didático do sexto ano, porém, questionamos: será esse o lugar ideal? E as recorrências? Vimos que é pouca a recorrência dos gêneros digitais no volume. E além de aparecer de forma tímida no livro didático, a abordagem que se faz dos gêneros digitais é deficiente, pois limita a possibilidade de utilização com maior frequência, uma vez que os conteúdos nos demais eixos não fazem referência e não utilizam aos gêneros.

\section{Percepção dos professores em relação ao livro didático e às concepções de gênero}

Neste item, analisamos os dados coletados nas reuniões dos grupos focais que realizamos na escola locus da pesquisa, nos meses de outubro e novembro de 2018. Em nosso primeiro encontro com os professores, discutimos sobre a formação de professores, procurando criar um espaço para que percepção que eles têm do livro didático de Português utilizado pela escola fosse explicitada, tentando captar como os professores de Língua Portuguesa têm se apropriado da temática para abordagem na sala de aula e quais as dificuldades mais frequentes apontadas pelos professores para trabalharem os gêneros digitais.

A análise tomou por base também os diálogos gravados nos encontros do grupo focal e nas entrevistas individuais semiestruturadas, no sentido de conhecer o trabalho realizado por esses professores no que diz respeito aos gêneros digitais e quais as impressões sobre o livro de Português adotado pela escola. 
Destacamos que os quatro professores colaboradores da pesquisa atuam no ensino de Língua Portuguesa na escola locus da pesquisa há mais de um ano, todos possuem formação específica (licenciatura) em Língua Portuguesa, representam 100\% dos professores de linguagem da escola lócus da pesquisa. Todavia, selecionamos a professora Kelly ${ }^{5}$ e o professor Manoel por atuarem nos sextos e sétimos anos, porque após a análise do material didático identificamos que é no sexto ano que o ensino dos gêneros digitais é contemplado.

A professora Kelly, estava com 36 anos quando foram iniciados os encontros dos grupos focais em outubro de 2018. A docente cursou Letras - Português/Inglês. Kelly iniciou suas atividades docentes ainda quando era discente do curso de Letras, que veio a concluído em 2010. Há 10 anos ela atua na docência de Língua Portuguesa em escolas públicas. Atualmente, a leciona no ensino fundamental da rede municipal de ensino e como professora monitora no ensino médio da rede estadual.

Durante os encontros de grupo, tendo em vista o objeto de estudo desta pesquisa, os gêneros textuais digitais, buscamos através de algumas provocações conhecer o que os professores entendiam por gêneros textuais. Para isso, fizemos vários questionamentos: Dentre os quais, o que eles entendiam por gêneros? A seguir, a transcrição da concepção de gêneros pela professora Kelly.

\section{Quadro 1 - Transcrição da Professora}

Os gêneros textuais são a base para se conseguir identificar aquilo que está lendo, saber se é uma fábula, um conto, se é uma tira ou se é uma charge, saber qual é o gênero. Então, eu entendo assim, é um embasamento para identificar aquilo que você está lendo, o texto, não é? O que ele está informando. Porque geralmente o texto informa alguma coisa, sobre algo, então, os gêneros textuais seriam mais ou menos assim.

Fonte: corpus da pesquisa

${ }^{5}$ Nome fictício. Utilizamos nomes fictícios para os professores colaboradores da pesquisa para preservar sua identificação. 
Vimos que a professora Kelly nos traz uma explicação interessante sobre o conceito de gêneros, analisando o trecho observa-se que a professora cita exemplos dos gêneros textuais não digitais, tais como: tira, conto e fábula.

É possível identificar que a professora procura conceituar gênero com base em Bakhtin (2016), pois é o teórico quem conceitua gênero referindo que a materialização dos textos se dá por enunciados, esses enunciados possuem forma e estilos próprios e são necessários para se entender e se fazer entendido durante o processo de produção textual. Com isso, percebemos que está muito bem fixado o conceito bakhtiniano dos gêneros, sendo uma herança dos PCN (BRASIL, 1998) de Língua Portuguesa, Bakhtin (2016, p. 11) expõe que o emprego da língua se dá pelos enunciados, ou pela forma de enunciado, e atualmente é reforçado pela nova Base Nacional Comum Curricular para o ensino fundamental - BNCC (BRASIL, 2017).

O segundo professor selecionado foi o docente Manoel tinha, que na época da pesquisa, tinha 29 anos de idade, é graduado em Letras-Português. Há pelo menos três anos ele relatou que atua como professor no ensino fundamental e não atuou em outros setores da educação. Durante o momento da entrevista, perguntamos também ao professor: o que ele entende por gêneros textuais? Respondeu o professor Manoel:

Quadro 2 - Transcrição 1 do professor Manoel

Os gêneros são fundamentais para o aprendizado do aluno, porque os gêneros estão presentes no dia a dia, tudo que nós vamos fazer, principalmente hoje em dia, nós utilizamos gêneros, para fazer um vestibular, um concurso, eles sempre estão presentes. A partir do convívio do dia a dia, de repente utilizar uma receita, o $\underline{e-m a i l}$, no dia a dia a utilização dele é muito importante para a gente (Grifos nossos).

Fonte: corpus da pesquisa

A assertiva sobre os gêneros exposta pelo professor Manoel dialoga com o entendimento de Miller (1984, p. 165), para o autor “um gênero não é apenas um padrão de formas ou um método para realizar nossos propósitos [...] os gêneros servem de chave para entender como participar das ações de uma comunidade.

Vale ressaltar, com relação ao livro didático analisado, que ele não conceitua gêneros digitais, ou seja, apesar de apresentar os gêneros, os autores não abordam de forma didática 
o conceito de gênero. No entanto, analisando as atividades e o conteúdo da unidade, identificamos que os autores se ocupam em destacar a função social do gênero, como é defendido por Miller (1984), pois o livro expõe a prática comunicativa permeada pelos gêneros e as interações sociais, de certo modo, resgatava também a noção de gênero em Bakhtin (2016), quando fala da característica multifacetada dos gêneros digitais.

Em nossos diálogos nos grupos focais e nas entrevistas, tratamos de temas que envolviam o livro didático de português e o ensino de gêneros, com o objetivo de entender o trabalho docente na sala de aula quanto a essa abordagem, questionamos então, de que forma os professores trabalham os gêneros textuais com seus alunos. Como seleciona os gêneros a serem explorados. Com esses questionamentos, pretendíamos saber se a professora Kelly tinha consolidado o conceito de gêneros textuais.

A professora inicia sua resposta na entrevista falando que trabalha os gêneros por meio de pesquisas, que geralmente ela leva para a sala de aula os gêneros que não estão no livro didático de Português.

Quadro 3 - Transcrição 2 da professora Kelly

os gêneros digitais, é uma realidade muito boa, porque hoje em dia a gente vive muito focado na tecnologia, então eles ajudam a levar para o aluno pensar, como escrever um e-mail, como enviar um e-mail, com as informações, se tem as assinaturas, se tem o vocativo.

Fonte: corpus da pesquisa

Kelly continua explicando que seleciona os gêneros recomendados pela matriz curricular e pelo livro didático, levando esses textos para discussão na sala. A professora destaca o estilo e a forma do e-mail, o uso do vocativo a assinatura e etc., confirmando o que Bakhtin (2016) apresenta, a estrutura composicional do gênero. No entanto, nos chama atenção, que mesmo sem ser questionada sobre os gêneros digitais, que seria o questionamento seguinte, conforme roteiro de entrevista no anexo, Kelly faz referência a tais gêneros. Quando questionada sobre os gêneros digitais, a professora responde: 
Quadro 4 - Transcrição 3 da professora Kelly

Os gêneros digitais são os gêneros que a gente usa envolvendo as novas tecnologias, como o $e$ mail, como blog, twitter, sucessivamente. Eu trabalhei mais, até agora, com o e-mail, para que os alunos observassem a estrutura do e-mail, como enviar o endereço, essas informações, mas o blog é também muito interessante.

Fonte: corpus da pesquisa

A professora trabalha o conteúdo e-mail como recomenda o livro didático utilizado pela escola. Como vimos na análise do livro do sexto ano, durante os diálogos a professora faz referência ao LDP referente ao volume seis de Cereja e Magalhães (2015), utilizado para ensino no sexto ano do ensino fundamental, e afirma que o conteúdo apresentado pelo LDP é interessante, afirma ainda, que vai além, busca em outras fontes, livros e pesquisa na internet outros gêneros para que os alunos não fiquem presos somente aqueles que são apresentados pelo livro.

Quanto às atividades com os gêneros digitais, a professora relatou que no ensino do gênero e-mail ela pedia para que seus alunos enviassem um e-mail para um outro colega da turma. Para Kelly a atividade com esse tipo de gênero é significativa.

Quadro 5 - Transcrição 4 da professora Kelly

Eu considero positiva, porque alguns alunos que têm e-mail, são conectados, já enviam e-mail, já tem e enviam para os colegas. Quando eu comecei a trabalhar, descobri que tem colegas que não tinham, então eu fui estimular, incentivar a criarem, a olhar se o pai tinha para pedir apoio dos pais. Fui mostrar como fazia, trouxe no laboratório para mostrar como fazer, como enviar, tudo isso, então é positivo[...] isso ajuda muito na escrita.

Fonte: corpus da pesquisa

Quando questionada sobre os gêneros que ela mais gosta de trabalhar, a professora Kelly respondeu que é o e-mail, porque na sua visão tem uma grande utilidade no cotidiano, além das possibilidades de trabalhar com a escrita. Além disso, os alunos gostam mais de utilizar gêneros relacionados com as redes sociais, destaca o twitter.

Perguntamos também ao professor Manoel sobre a utilização dos gêneros digitais, o professor afirmou que geralmente faz um diagnóstico da turma para assim poder selecionar os gêneros a serem discutidos nas aulas, relatando que utiliza o e-mail em suas atividades pedagógicas. O professor explica que antes de trabalhar com o gênero procura saber 
quem já o conhece. No caso do e-mail, pergunta quem possui uma conta e questiona também quem sabe utilizar, pela fala do professor Manoel percebe-se que ele se preocupa com a realidade cultural dos alunos.

Ao analisarmos as falas do professor Manoel, observa-se que ele possui consciência da necessidade do reconhecimento da competência cultura digital abordada pela nova BNCC (BRASIL, 2017) para o ensino fundamental e assim como Braga (2010) ele reconhece o e-mail como um gênero importante para a sociedade e para o indivíduo interagir nos ambientes informáticos.

Quando é questionado sobre os gêneros digitais, o professor fala que eles são bastante utilizados e afirma que os alunos chegam no quinto e sexto ano já com a consciência da abordagem desses gêneros. Nesse momento, ele começa a exemplificar, acrescenta Manoel.

Quadro 6 - Transcrição 2 do professor Manoel

O Whats $A p p$, o próprio e-mail e outros gêneros digitais são muito importantes e eu sempre abordo em sala de aula, de diferentes maneiras.

Fonte: corpus da pesquisa

O professor Manoel, por iniciativa própria criou junto com a turma um endereço eletrônico para ser utilizado como meio de interação entre eles. Os alunos utilizam esse $e$ mail para a entrega de atividades avaliativas solicitadas pelo professor. Com essa postura, diz o professor, que os alunos tiveram uma reação positiva a essa atitude, Manoel relata essa reação, relata o professor:

Quadro 7 - Transcrição 3 do professor Manoel

Os alunos gostam, porque facilita, eles enviam para meu e-mail o trabalho pronto, eu corrijo e reenvio para eles. Criamos também um grupo no Whats $A p p$, um grupo de estudos que eu coloco algumas perguntas, utilizamos o grupo para comunicação também. [...] São muito importantes, isso não tem o que questionar.

Fonte: corpus da pesquisa

A professora Kelly acrescenta que o LDP utilizado pela escola apresenta o que está proposto na matriz curricular da escola e atende a necessidade da aula. Quanto aos estudantes, a professora disse não perceber dificuldades em conhecer os gêneros, mas que 
existe restrições de acesso, pois alguns alunos não possuem acesso às tecnologias, como: computador, smartphones, tablets e etc. A professora Kelly destacou que a escola é muito colaborativa em facilitar o acesso aos ambientes de tecnologia na escola, por exemplo, laboratório de informática, sala de recursos especiais e etc.

Analisando as falas da professora Kelly e do professor Manoel tanto nos diálogos de grupo focal, quanto na entrevista semiestruturada, percebemos que os professores têm conhecimento quanto aos gêneros digitais, sabem diferenciar os gêneros textuais tradicionais e os emergentes do contexto digital, levam a prática para a sala de aula e avaliam positivamente o LPD utilizado pela escola.

\section{Últimas palavras}

Este artigo é uma síntese de uma pesquisa de mestrado que teve como objetivo geral analisar os gêneros digitais que são abordados pelos livros didáticos de Língua Portuguesa, nos anos finais do ensino fundamental, em coleções recomendadas pelo PNLD 2017-2019, em relação à forma, ao estilo e à estrutura composicional, contribuindo assim com o conhecimento sobre os gêneros digitais.

Quanto a problematização da presença dos gêneros digitais nos livros didáticos de Português, os resultados desta pesquisa apontam que os livros didáticos do sexto ao nono ano apresentam os gêneros digitais, no entanto, somente no livro do sexto ano é que esse tipo de gênero é trabalhado de uma forma mais significativa. Após a análise do material didático, vimos que o livro aborda os gêneros: e-mail, blog e twitter, focando no ensino da forma, do estilo e da estrutura composicional dos gêneros. Se observou nas análises que nos demais volumes, os gêneros digitais são citados como pretexto para trabalhar outras categorias linguísticas.

Em relação à abordagem dos gêneros digitais na sala de aula e no ensino de Língua Portuguesa, constatamos que o livro didático apresenta atividades que contemplam o uso dos gêneros digitais. E que os autores dos livros didáticos analisados direcionam a sequência didática no sentido de permitir ao professor explorar na prática o ensino de gêneros, trabalhando os conceitos e as práticas sociais. 
A pesquisa constatou também que os professores possuem conhecimento conceitual sobre os gêneros digitais e os utilizam em práticas docentes. Exploram a utilização dos gêneros mesmo nas unidades em que os gêneros não são abordados, ou ainda, como meio de interação e comunicação com os estudantes.

No entanto, com base nas análises, observamos que ainda há uma lacuna na formação continuada de professores, sobretudo, formação voltada para apropriação da cultura digital, pudemos observar que os professores enxergam nos gêneros digitais uma forma de se aproximar da realidade cultural dos alunos.

Os professores relatam também que as escolas possuem laboratórios e tecnologias emergentes a serem exploradas. Afirmam que há problemas de infraestrutura na maioria das escolas públicas, o que de certa forma compromete a abordagem dos gêneros digitais em sua forma, estilo, e estrutura composicional. Os professores ainda afirmam que não possuem dificuldades na utilização dos gêneros digitais com seus alunos.

\title{
DIGITAL GENRES IN PORTUGUESE TEACHING BOOKS: AN APPROACH FOCUSED ON THE TEACHING BOOK AND TEACHER'S CONCEPTION
}

\begin{abstract}
This article is synthesis of a Master's dissertation in Education, which aimed to analyze the digital textual genres that are addressed by Portuguese language textbooks, in the final years of elementary school. It is a qualitative research of the case study type and was developed in a public school in the municipal education system, in a city on the southern coast of the State of Alagoas. To achieve the objective, documentary analysis and meetings in focus groups with Portuguese language teachers who worked in elementary school were carried out. The methodological procedures used were documentary analysis of textbook volumes from the sixth to the ninth year of elementary school, as well as interviews with teachers. To understand the concepts of the speech genres, we used Bakhtin (1997, 2016), Marcuschi (2008, 2010) and Miller (2012) as a basis. As for the specific knowledge of digital genres, we rely on Marcuschi and Xavier (2010). The results show that textbooks from the sixth to the ninth year present the digital genres, however, it is only in the sixth year book that this type of genre is worked in a more meaningful way, in the others they are cited as pretext to work with others language categories. They also point out that the textbooks for elementary school provide guidance on the use of digital genres in elementary school classes. We also found that teachers have a positive perception of the textbook used by the school and that they have knowledge about digital genres and use them in practice.
\end{abstract}

KEYWORDS: Portuguese language; Textbook; Digital Genres. 


\section{REFERÊNCIAS}

ALVES-MAZZOTTI, A. J; GEWANDSZNAJDER, F. O método das ciências naturais e sociais: pesquisa quantitativa e qualitativa. 2. ed., São Paulo: Pioneira, 2004.

ARAUJO, J. C. R. Transmutação de gêneros na web: a emergência do chat. In: MARCUSCHI, L. A.; XAVIER, A. C. (Orgs). Hipertexto e gêneros digitais: novas formas de construção de sentido. 3. ed., São Paulo: Cortez, 2010.

BAKHTIN. M. M. Estética da criação verbal. 2. ed., São Paulo: Martins Fontes, 1997. Os gêneros do discurso. São Paulo: Editora 34, 2016.

BAZERMAN, C. Gênero, agência e escrita. 2. ed., São Paulo: Cortez, 2011.

BORGES, M. M. M. (Org). A emergência do conceito de gênero do discurso no Brasil. In: FERNANDES, E. M. F. Gêneros do discurso: dialogando com Bakhtin. Campinas: Pontes Editora, 2017.

BRAGA, D. B. A comunicação interativa em ambientes hipermídia: as vantagens da hipermodalidade para o aprendizado no meio digital. In: MARCUSCHI, L. A.; XAVIER, A. C. (Orgs). Hipertexto e gêneros digitais: novas formas de construção de sentido. 3. ed. São Paulo: Cortez, 2010.

BRASIL. Secretaria de Educação Fundamental. Parâmetros curriculares nacionais: terceiro e quarto ciclos do ensino fundamental: língua portuguesa. Brasília: MEC/SEF, 1998.

BRASIL. Ministério da Educação. Secretaria da Educação Básica. Base Nacional Comum Curricular. Brasília, DF, 2017. Disponível em: http://basenacionalco-

mum.mec.gov.br/wp-content/uploads/2017/02/bncc-20dez-site.pdf. Acesso em 01 de junho de 2018.

CEREJA, W. R; MAGALHÃES, T.C. Português: linguagens 6. 9. Ed. Reformada. São Paulo: Saraiva, 2015a.

. Português: linguagens 7. 9. ed., reformada. São Paulo: Saraiva, $2015 \mathrm{~b}$.

. Português: linguagens $8^{\circ}$ ano. 9. ed., reformada. São Paulo: Saraiva, 2015c.

. Português: linguagens $9^{\circ}$ ano. 9. ed., reformada. São Paulo: Saraiva, 2015d.

GATTI, B. A. Grupo focal na pesquisa em ciências sociais e humanas. Brasília: Liber Livro Editora, 2005.

KOMESU, F. C. Blogs e as práticas de escrita sobre si na internet. In: MARCUSCHI, L. A.; XAVIER, A. C. (Orgs). Hipertexto e gêneros digitais: novas formas de construção de sentido. 3. ed., São Paulo: Cortez, 2010.

LEVY, P. Cibercultura. São Paulo: Ed. 34, 1999. 
MARCUSCHI, L. A. Produção textual, análise de gêneros e compreensão. São Paulo: Parábola Editorial, 2008.

- Gêneros textuais no ensino de língua. In: MARCUSCHI, L. A. Producão textual, análise de gêneros e compreensão. São Paulo: Parábola Editorial, 2008.

MARCUSCHI, L. A.; XAVIER, A. C. (Orgs). Hipertexto e gêneros digitais: novas formas de construção de sentido. 3. ed., São Paulo: Cortez, 2010.

MILLER, C. R. Gênero textual, agência e tecnologia. São Paulo: Parábola Editorial, 2012. Genre as Social Action. Madison: Quarterly Journal of Speech 70, 1984.

MORAES, R; GALIAZZI, M. C. Análise textual discursiva. 3. Ed. Ijuí: Ed. Unijuí, 2016.

OLIVEIRA, T. L. M.; DIAS, R. Multimodalidade ontem e hoje nas homepages do yahoo: trilhando uma análise diacrônica de textos multimodais. In: KERSCH, D. F.; COSCARELLI, C.V.; CANI, J. B. (Orgs.). Multiletramentos e multimodalidade: ações pedagógicas aplicadas à linguagem. Campinas: Pontes Editora, 2016.

PAIVA, V. L. M. O. E-mail: um novo gênero textual. In: MARCUSCHI, L. A.; XAVIER, A. C. (Orgs). Hipertexto e gêneros digitais: novas formas de construção de sentido. 3. ed., São Paulo: Cortez, 2010.

PIMENTEL, F. S. C.; COSTA, C. J. S. A. A cultura digital no cotidiano das crianças: apropriação, reflexos e descompassos na educação formal. In: Interfaces Científicas, Aracaju v. 6, n. 3, p. 135-146, jun. 2018.

XAVIER, A. C. Leitura, texto e hipertexto. In: MARCUSCHI, L. A.; XAVIER, A. C. (Orgs.). Hipertexto e gêneros digitais: novas formas de construção de sentido. 3. ed., São Paulo: Cortez. 2010.

YIN, R. K. Estudo de caso: planejamento e métodos. 3. ed., Porto Alegre: Bookman, 2005.

Recebido em: 15/03/2020.

Aprovado em: 07/05/2020. 